

\section{VACUUM CHAMBER HEAT-TRANSMISSION ANALYSIS}

By Walter W. Guy and Wilbert E. Ellis

\section{Manned Spacecraft Center}

Houston, Texas 


\begin{abstract}
An analytical investigation was conducted to study the effect of the test-chamber pressure level on the accuracy of deep-space heat-transfer simulation, using as parameters the test vehicle emittance and surface temperature. The study reveals that, with the exception of extremely low temperature conditions, a test-chamber pressure of approximately $10^{-5} \mathrm{~mm} \mathrm{Hg}$ provides the best thermal simulation.
\end{abstract}




\section{VACUUM CHAMBER HEAT-TRANSMISSION ANALYSIS}

By Walter W. Guy and Wilbert E. Ellis

Manned Spacecraft Center

\section{SUMMARY}

An analytical investigation was conducted to study the effect of the test-chamber pressure level on the accuracy of deep-space heat-transfer simulation, using as parameters the vehicle emittance and surface temperature.

The greatest portion of heat transfer would be through gas conduction and free convection in an environmental control chamber with Apollo test capability, at atmospheric pressure. This, as well as using a nitrogen cold wall to approximate the near-absolute zero of space, introduces inconsistencies into the simulation.

The study reveals that, with the exception of extremely low temperature conditions, a test-chamber pressure of approximately $10^{-5} \mathrm{~mm} \mathrm{Hg}$ provides the best thermal simulation.

\section{INTRODUCTION}

The accurate simulation of a deep-space environment is mandatory for valid vehicle and component thermal evaluation and heat-transfer research. Since radiation is the only mode of external thermal transfer in deep space, other means of heat transmission (conduction and convection) introduce errors in thermally simulating a deep-space environment. These errors are not the only source of erroneous data. Using a nitrogen cold wall to approximate the near-absolute zero of space also introduces inconsistencies into the simulation. The purpose of this paper is to present the results of an analytical investigation into the effect of the test-chamber pressure level on the accuracy of deep-space heat-transfer simulation.

\section{SYMBOLS}

$A_{1} \quad$ vehicle lateral area, $\mathrm{ft}^{2}$

$A_{2}$ cold-wall lateral area, $\mathrm{ft}^{2}$ 
$c_{p} \quad$ specific heat capacity at constant pressure, Btu $/ \mathrm{lb}-{ }^{\circ} \mathrm{R}$

$c_{v}$ specific heat capacity at constant volume, Btu $/ 1 b-{ }^{\circ} R$

$\mathrm{d}_{1} \quad$ vehicle diameter, $\mathrm{ft}$

$d_{2}$ cold-wall diameter, $f t$

M molecular weight of residual gas

p pressure of residual gas, $1 \mathrm{~b} / \mathrm{ft}^{2}$

q heat flux, Btu/hr-ft ${ }^{2}$

$R_{M} \quad$ universal gas constant, ft-lb/mole- ${ }^{\circ} R$

$\mathrm{T}$ temperature of residual gas, ${ }^{\circ} \mathrm{R}$

$T_{1} \quad$ vehicle surface temperature, ${ }^{\circ} \mathrm{R}$

$\mathbf{T}_{2} \quad$ cold-wall temperature, ${ }^{\circ} \mathrm{R}$

$\mathrm{U}$ heat-transfer coefficient, Btu/hr-ft ${ }^{2}-{ }^{\circ} \mathrm{R}$

$\alpha_{1}$ vehicle accommodation coefficient

$\alpha_{2} \quad$ cold-wall accommodation coefficient

$\gamma \quad c_{p} / c_{v}$

$\Delta \mathrm{T}_{1} \quad$ vehicle surface temperature error

$\epsilon_{1} \quad$ vehicle emittance

$\epsilon_{2} \quad$ cold-wall emittance

$\sigma \quad$ Stefan-Boltzmann constant, Btu/hr-ft ${ }^{2}-{ }^{\circ} \mathrm{R}^{4}$

$\phi \quad$ percent error 


\section{VACUUM CHAMBER HEAT-TRANSFER EQUATIONS}

In an environmental control chamber with Apollo test capability, the following

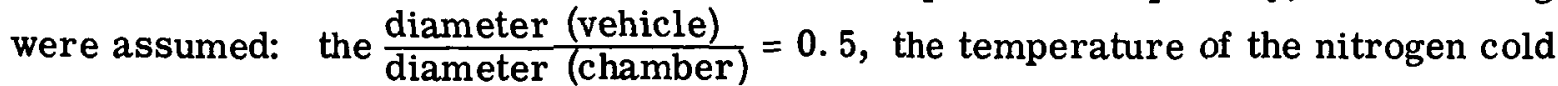
wall $=140^{\circ} \mathrm{R}$, the emittance $\epsilon_{2}$ of the cold wall $=0.9$, the operating pressure range $=10^{-3}$ through $10^{-5} \mathrm{~mm} \mathrm{Hg}$.

The greatest portion of heat transfer would be through gas conduction and free convection in an environmental control chamber with Apollo test capability, at atmospheric pressure. As the pressure is reduced to the operating range, $10^{-3} \mathrm{~mm} \mathrm{Hg}$, the gas behaves more like separate molecules than gas masses. This alters the mode of heat conduction from a multicollisional diffusion process to "free-molecule" heat transport, and, thus, significantly changes the magnitude of the heat conduction (ref.l). Although free convection (the transfer of heat propagated by the buoyant movement of a fluid due to a change in density within a fluid by reason of its close proximity with a body of a different temperature) is practically nonexistent at this reduced pressure, radiation heat transfer is not significantly affected.

The Stefan-Boltzmann equation (ref. 2), as adapted for radiation between concentric cylinders, was used throughout this analysis.

$$
\mathrm{q}_{\text {chamber }}=\sigma\left(\frac{\epsilon_{1} \epsilon_{2}}{\epsilon_{2}+\frac{\mathrm{A}_{1}}{\mathrm{~A}_{2}}\left(1-\epsilon_{2} \epsilon_{1}\right)}\right)\left(\mathrm{T}_{1}^{4}-\mathrm{T}_{2}^{4}\right) \mathrm{Btu} / \mathrm{hr}-\mathrm{ft}^{2}
$$

Neither the total pressure nor the surrounding air affects the validity of the Stefan-Boltzmann radiation equation.

The Knudsen equation (ref. 3) is accurate only in the region of "free-molecule" conduction. $^{1}$

$$
\mathrm{q}_{\text {conducted }}=\frac{1}{2}\left(\frac{\alpha_{1} \alpha_{2}}{\mathrm{\alpha}_{2}+\frac{\mathrm{d}_{1}}{\mathrm{~d}_{2}} 1-\alpha_{2} \alpha_{1}}\right) \frac{\gamma+1}{\gamma-1} \sqrt{\frac{\mathrm{R}_{\mathrm{M}}}{2 \pi}} \frac{\mathrm{p}}{\sqrt{\mathrm{TM}}}\left(\mathrm{T}_{1}-\mathrm{T}_{2}\right)^{\mathrm{Btu} / \mathrm{hr}-\mathrm{ft}^{2}}
$$

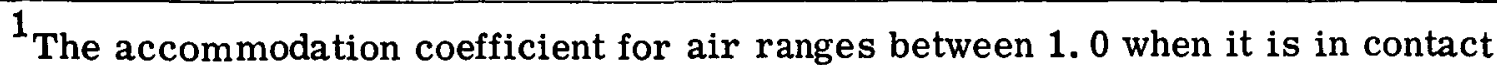
with a surface at $76^{\circ} \mathrm{K}$ and 0.85 at a surface temperature of $300^{\circ} \mathrm{K}$ (ref. 3). The residual gas temperature can be determined as the numerical average of the vehicle surface temperature and the chamber wall temperature. 
This low-conduction region is established at various pressure levels for different gases and separation distances of the heat-transfer surfaces. Gas conduction in the pressure range above the free molecular zone is considerably greater than that indicated by the Knudsen equation. No attempt was made to define the point at which the region of "free molecule" conduction was established, since the simulator geometry, the test object geometry, and the exact composition of residual gases are points of conjecture. Therefore, for this analysis the Knudsen equation will be assumed valid at pressures of $10^{-3} \mathrm{~mm} \mathrm{Hg}$ and below. Any deviation encountered because of this assumption will result in "lower-than-actual" values for gas conduction computed at the upper portion of the $10^{-3}$ to $10^{-5} \mathrm{~mm} \mathrm{Hg}$ range.

\section{EFFECTS OF GAS CONDUCTION IN A VACUUM CHAMBER}

The importance of gas conduction in a vacuum chamber can be illustrated with a practical example. To determine a temperature profile for a launch vehicle during the cool-off period after aerodynamic exit heating, a chamber such as the one described previously would be needed. If the chamber were evacuated to $10^{-3} \mathrm{~mm} \mathrm{Hg}$ and the vehicle surface heated, the heat rejected could be accurately determined by temperature monitoring. To assume that this heat rejection was by radiation (as will be the case in deep space) would be incorrect. In fact, for an aluminum-skin vehicle with a nominal emittance of 0.05 and an effective surface temperature in the $700^{\circ} \mathrm{R}$ range, the error would be approximately 48 percent (fig. 1). This error could be

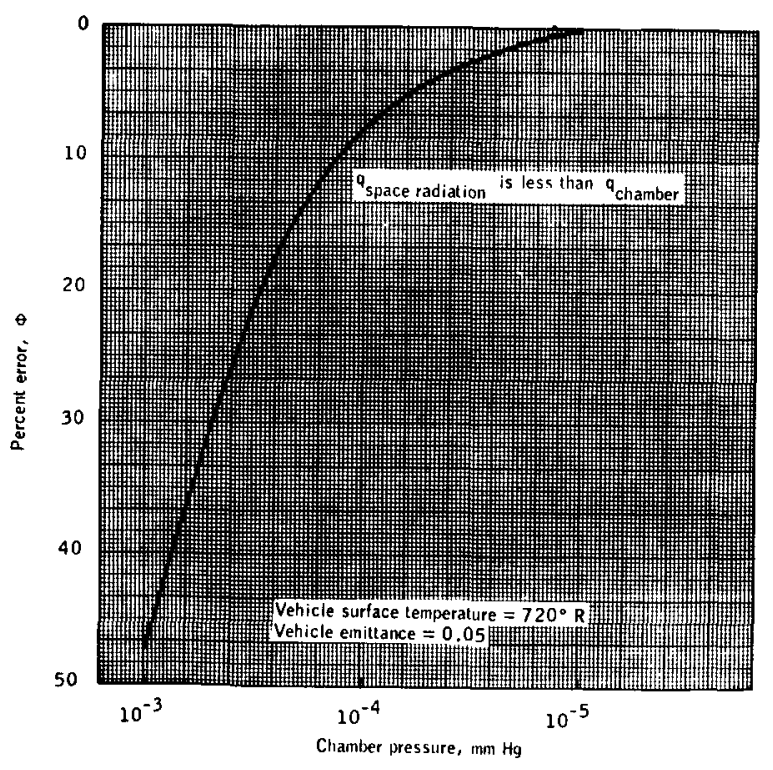
reduced to approximately 8 percent by a pressure reduction to $10^{-4} \mathrm{~mm} \mathrm{Hg}$ and to almost 0.2 percent at $10^{-5} \mathrm{~mm} \mathrm{Hg}$. Thus, gas-conduction heat transfer appreciably affects test results.

Figure 2 represents the composition of the total heat flux to the chamber wall from objects at various surface temperatures. The first curve $(0)$ is radiation; the second curve $(\Delta)$ is gas conduction; and the last $(\square)$ is the total heat flux to the cold wall (that is, a summation of the conduction and radiation).

Figure 3 plots the total heat flux for a chamber at $10^{-3}, 10^{-4}$, and $10^{-5} \mathrm{~mm} \mathrm{Hg}$, and a vehicle emittance of 0.75 . In addition,

Figure 1. - Heat transfer error in chamber simulation of space. 


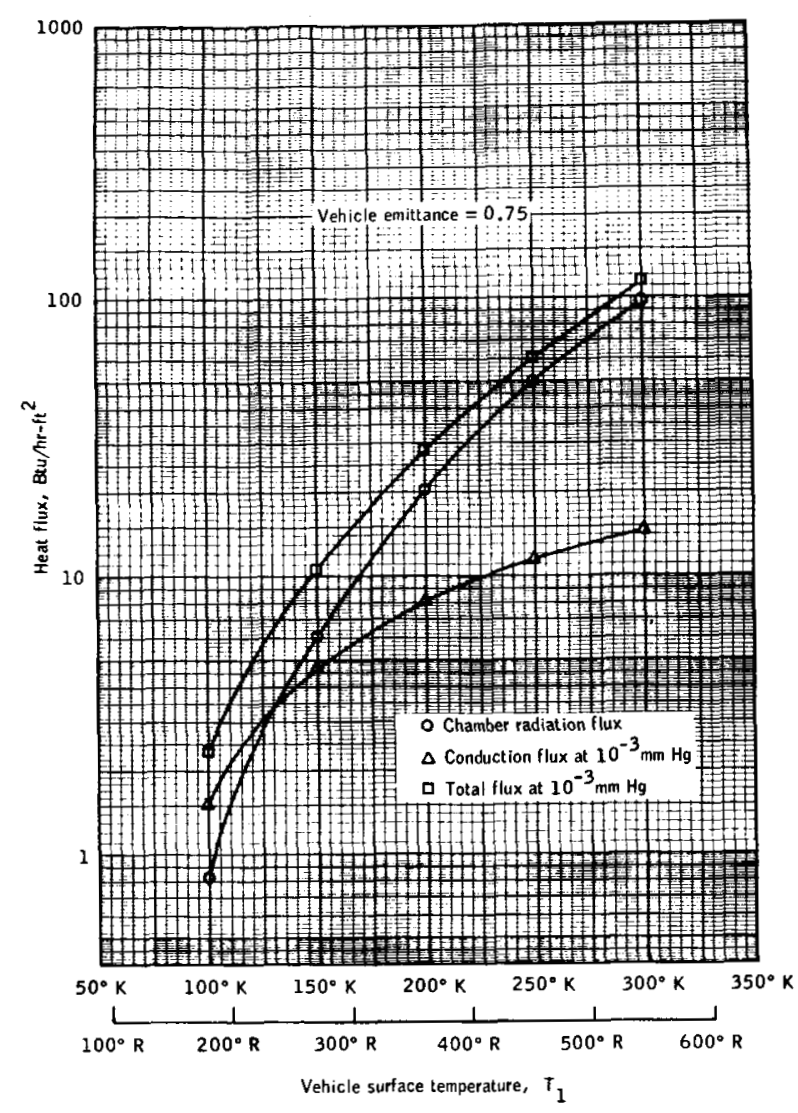

Figure 2. - Composition of chamber heat flux.

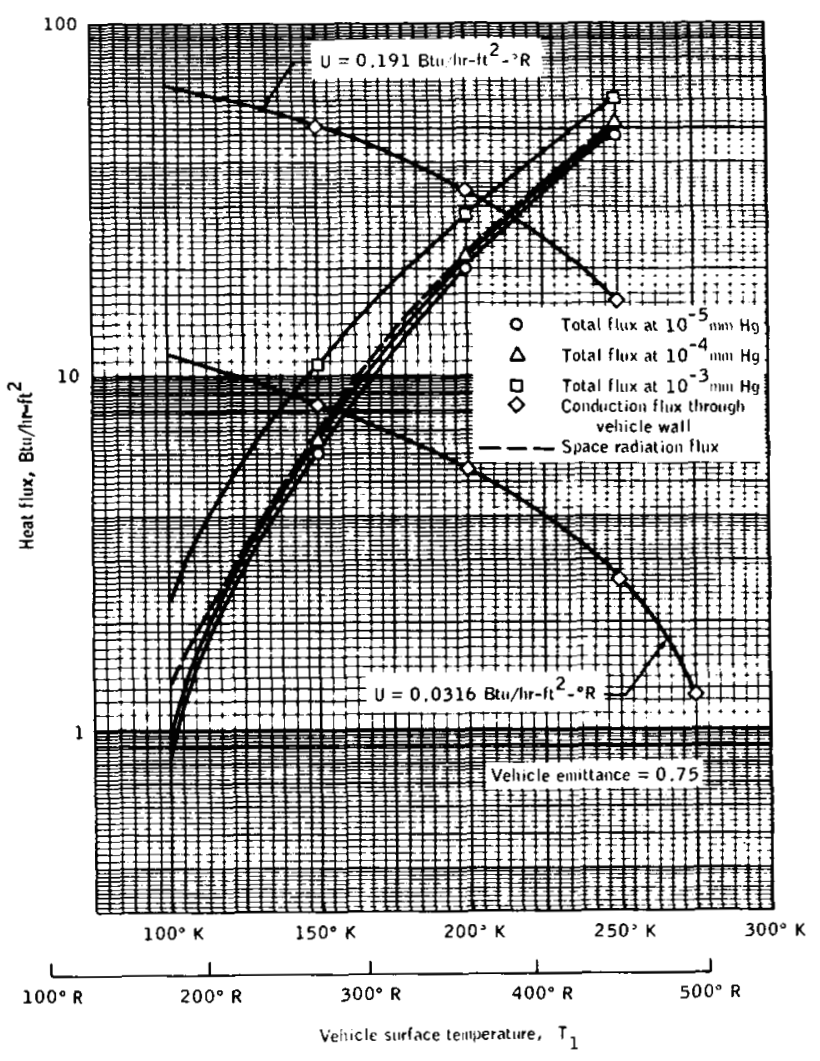

Figure 3. - Heat transfer for equilibrium condition.

the heat flux that would be radiated from the vehicle in outer space is plotted

$$
\left(q_{\text {space radiation }}=\epsilon_{1} \sigma A_{1} T_{1}{ }^{4}\right)
$$

This information can be utilized to determine simulation-temperature errors by crossplotting the data of a particular problem.

For example, if the test object were a typical manned spacecraft and a realistic deep-space surface equilihrium temperature were desired, the aforementioned chamber would again be needed. It is assumed that the spacecraft is divided into zones of different thermal-conciuction characteristics and that the overall coefficients of heat transfer lie within the band $U=0.0136$ through $0.191 \mathrm{Btu} / \mathrm{hr}-\mathrm{ft}^{2}-\mathrm{R}$. These two boundary values will be used for illustration. By using a nominal interior temperature of $75^{\circ} \mathrm{F}$ and by allowing the vehicle outer-surface temperature to vary, a heatconduction curve for each of the $U$ values can be plotted

$$
\left[\mathrm{q}=\mathrm{UA}_{1}\left(535-\mathrm{T}_{1}\right)\right]
$$


The intersections of these two curves $(0)$ with the total-heat-flux curves for $10^{-3}, 10^{-4}$, and $10^{-5} \mathrm{~mm} \mathrm{Hg}$ and the space-radiation curve determine vehicle surface equilibrium temperatures.

Vehicle surface equilibrium temperatures at the three operating pressures are shown in figure 4 . The temperatures vary more than $18^{\circ} \mathrm{R}$ for either overall coefmcient of heat transmission.

The vehicle surface temperaturedifference error encountered in the simulator over the actual deep-space condition is shown in figure 5 . This indicates that for the $U$ values considered, there is a chamber pressure that results in zero error. That is, the simulated temperature is the actual deep-space surtiace equilibrium temperature. Could this combination of pressure and temperature be duplicated, perfect simulation would be achieved. However, this is of more academic interest than practical value, since it requires knowing the deep-space surface equilibrium temperature which in most cases is the reason for conducting the chamber simulation. Even if the analytical determination of this temperature is sufficiently accurate to establish the required chamber-pressure level, great difficulty is encountered in obtaining and maintaining a precise pressure ambient in a large chamber.

These two examples are not meant to be indicative of every type of problem that will be encountered. Rather than trying to find representative problems to cover the range of test conditions, a better understanding can be achieved by pursuing a more general line of analysis.

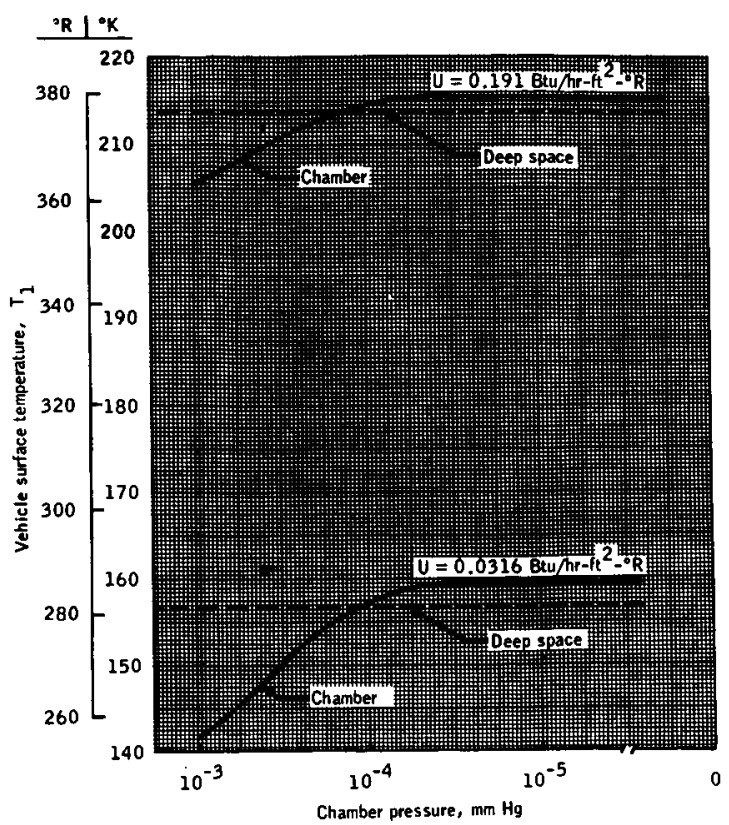

Figure 4. - Equilibrium temperature conditions.

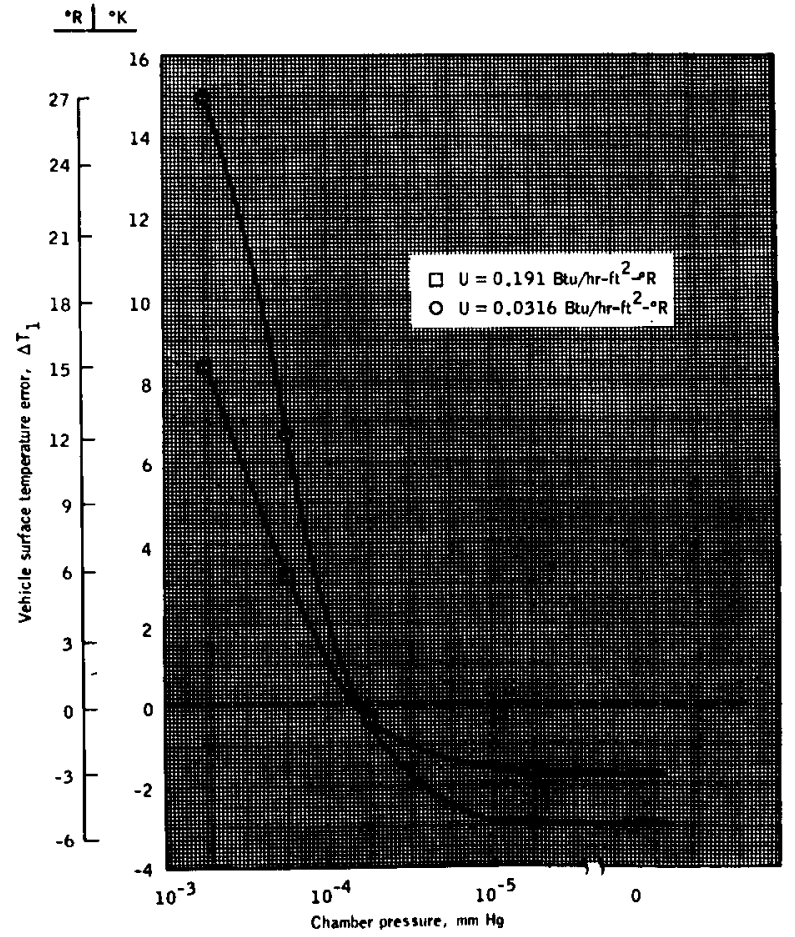

Figure 5. - Simulation temperature error. 


\section{RESULTS AND DISCUSSION}

The duplication of the thermal characteristics of a deep-space environment is the object of a chamber test run; the accuracy of the simulation is the measure of success. The deviation from perfect simulation is the difference in heat transfer under deepspace conditions and heat transfer in the chamber. This error may be positive or negative depending on test conditions. The three parameters that most affect this error are the test vehicle emittance, the surface temperature, and the chamber absolute pressure. By plotting simulation error against chamber pressure at a fixed vehicle surface temperature for various emittance values, a more complete picture is given. The pressure was confined to the $10^{-3}$ to $10^{-5} \mathrm{~mm} \mathrm{Hg}$ range, while the emittance was allowed to vary from 0.05 to 0.95 . Separate figures were drawn for vehicle surface temperatures of $720^{\circ} \mathrm{R}$ (fig. 6), $540^{\circ} \mathrm{R}$ (fig. 7), $360^{\circ} \mathrm{R}$ (fig. 8), and $180^{\circ} \mathrm{R}$ (fig. 9).

Figures 6, 7, and 8 indicate that reasonable accuracy was maintained for all emittances at $10^{-5} \mathrm{~mm} \mathrm{Hg}$. With decreasing surface temperature, progressively more error was encountered at $10^{-3} \mathrm{~mm} \mathrm{Hg}$.

This generalization was false when applied to the $180^{\circ} \mathrm{R}$ test vehicle in figure 9 . The error was considerable at either $10^{-3}$ or $10^{-5} \mathrm{~mm} \mathrm{Hg}$. This can be explained by realizing that the nitrogen cold-wall temperature was only $140^{\circ} \mathrm{R}$, thus introducing a

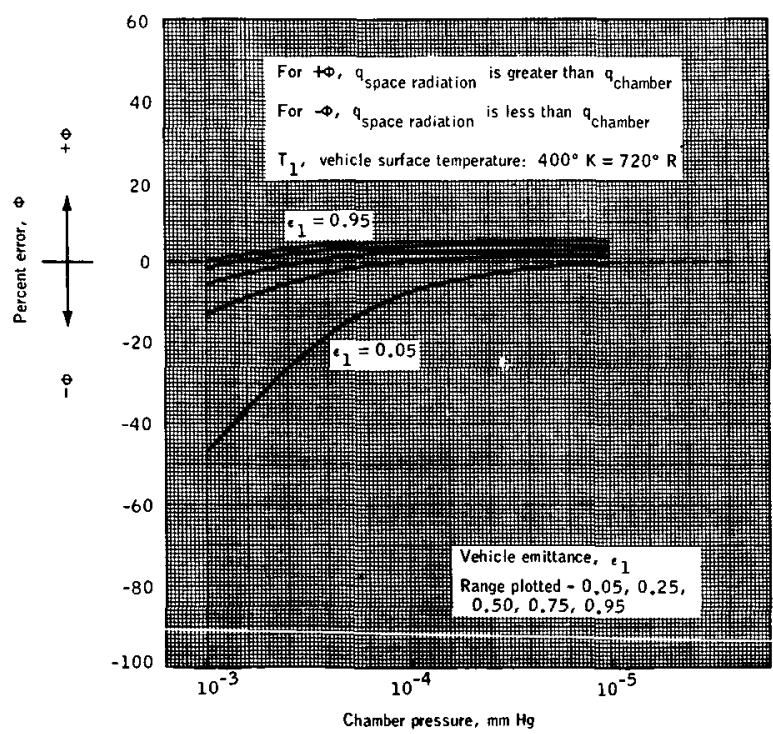

Figure 6. - Simulation error in heat transmission $\left(\mathrm{T}_{1}=720^{\circ} \mathrm{R}\right)$.

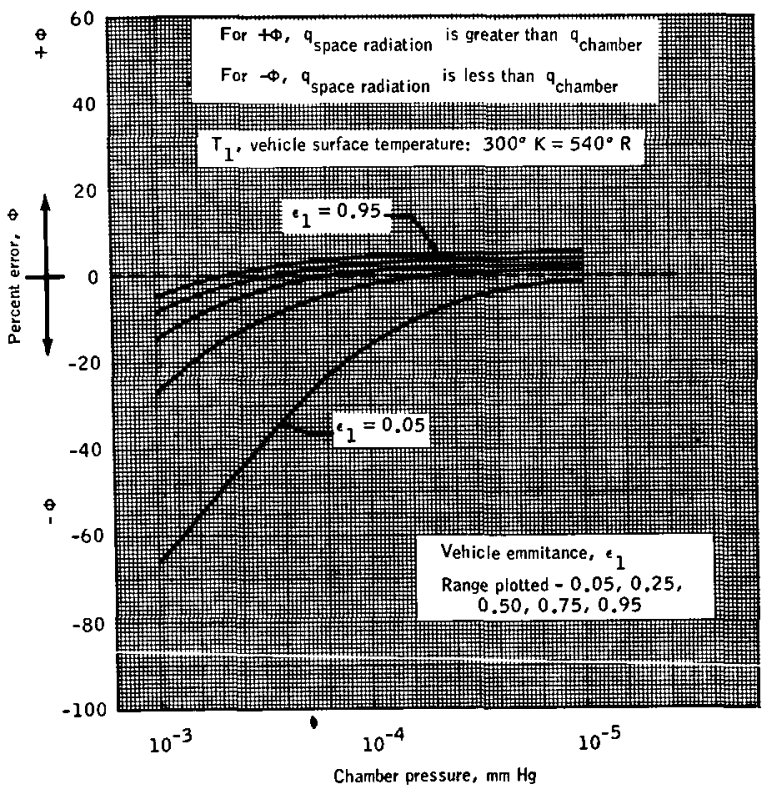

Figure 7. - Simulation error in heat transmission $\left(T_{1}=540^{\circ} \mathrm{R}\right)$. 


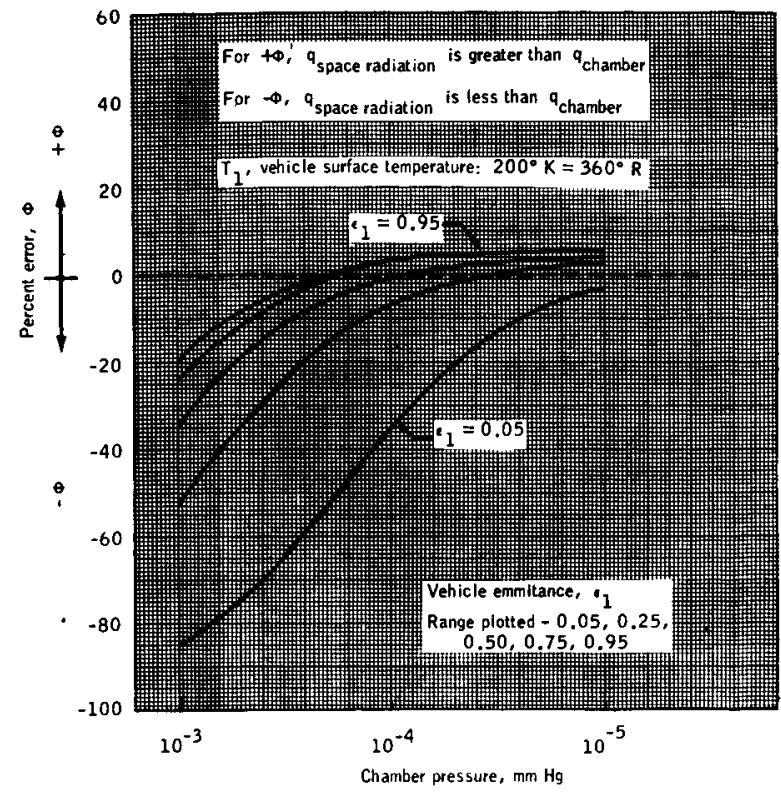

Figure 8. - Simulation error in heat transmission $\left(T_{1}=360^{\circ} \mathrm{F}\right)$.

large radiation error at the lower vehicle surface temperature. If work is to be done in this low-temperature region, reasonable accuracy can be obtained by using an $8^{\circ} \mathrm{R}$ helium cold wall and decreasing the chamber pressure by a factor of 10 to $10^{-6} \mathrm{~mm} \mathrm{Hg}$ (fig. 10).

Figure 11 was included to give a general picture of the maximum error in deep-space heat-transmission simulation encountered at any vehicle surface temperature. At $10^{-5} \mathrm{~mm} \mathrm{Hg}$, this maximum error (for test-vehicle emittances ranging from 0.05 to 0.95 and surface temperatures ranging from $360^{\circ} \mathrm{R}$ to $720^{\circ} \mathrm{R}$ ) was approximately 6 percent. At the higher pressure, $10^{-3} \mathrm{~mm} \mathrm{Hg}$ (for the same ranges of emittance and temperature), the maximum error was in excess of 80 percent. In the vehicle surface low-temperature range, $180^{\circ} \mathrm{R}$, the maximum error for the emittance range of 0.05 to 0.95 was greater than 50 percent

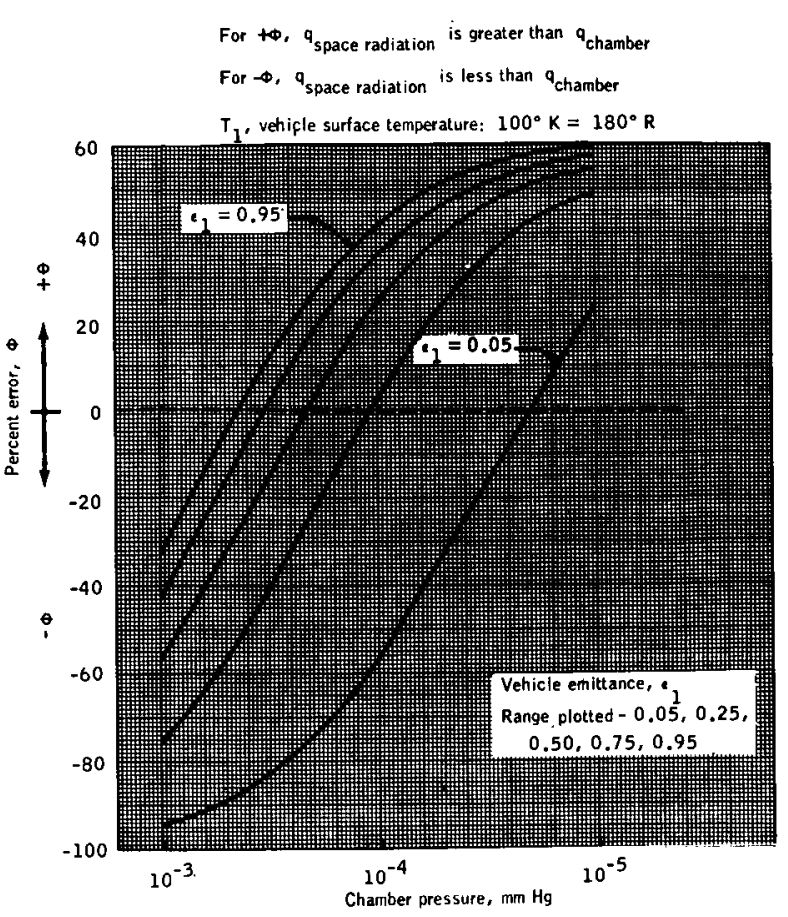

Figure 9. - Simulation error in heat transmission $\left(T_{1}=180^{\circ} R\right)$.

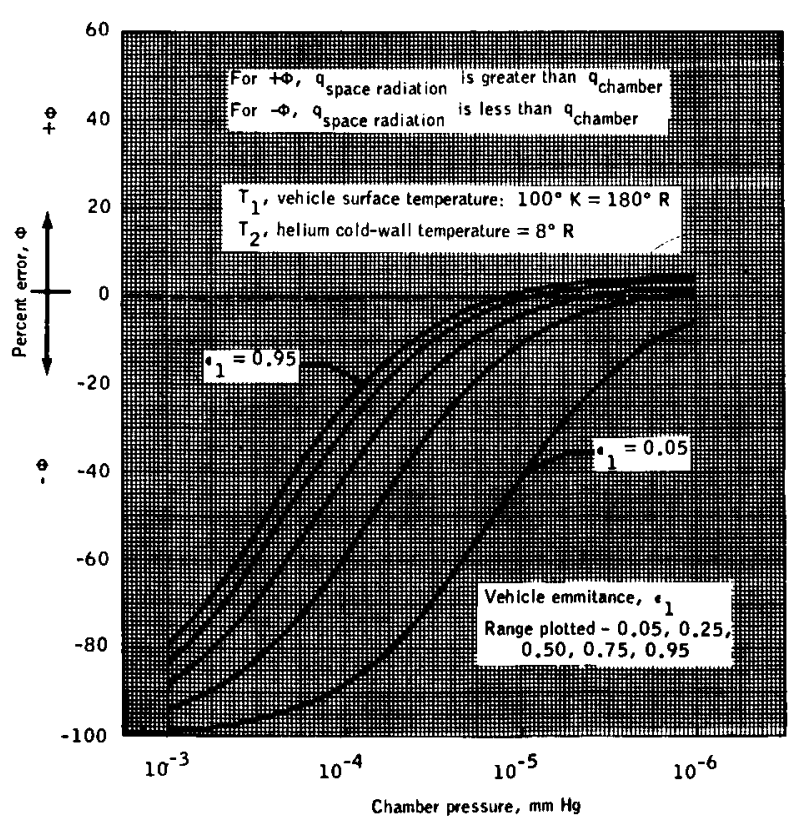

Figure 10. - Simulation error in heat transmission $\left(T_{1}=180^{\circ} R, T_{2}=8^{\circ} R\right)$. 


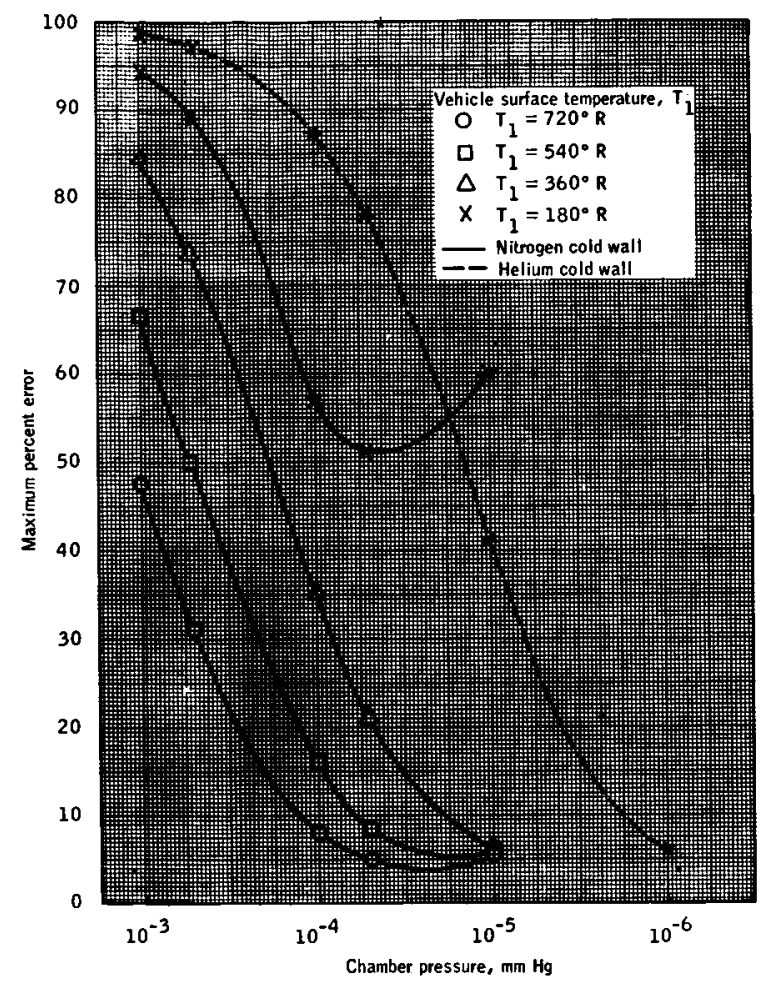

Figure 11. - Maximum heat transfer error for vehicle temperatures of $180^{\circ} \mathrm{R}, 320^{\circ} \mathrm{R}, 540^{\circ} \mathrm{R}, 720^{\circ} \mathrm{R}$. for pressures $10^{-3}$ through $10^{-5} \mathrm{~mm} \mathrm{Hg}$. This error can be reduced to about 6 percent by using an $8^{\circ} \mathrm{R}$ helium cold wall and reducing the chamber pressure to $10^{-6} \mathrm{~mm} \mathrm{Hg}$. It should be noted that the helium cold wall does not reduce the error at $10^{-3} \mathrm{~mm} \mathrm{Hg}$.

\section{CONCLUDING REMARKS}

An analytical investigation was conducted to study the effect of the test-chamber pressure level on the accuracy of deep-space heat-transfer simulation, using as parameters the vehicle emittance and surface temperature.

A conclusion stating a definite course of action is impossible with the multitude of variable parameter $s$, but a general statement can be made. With the exception of extremely low-temperature work, a test-chamber pressure of $10^{-5} \mathrm{~mm} \mathrm{Hg}$ gives the best thermal simulation accuracy for all parameters considered.

Manned Spacecraft Center

National Aeronautics and Space Administration

Houston, Texas, July 14, 1966

914-50-80-02-72 


\section{REFERENCES}

1. Jakob, Max: Heat Transfer, Vol. I. John Wiley and Sons, Inc., Seventh Printing, 1959, p. 71.

2. Jakob, Max; and Hawkins, George A. : Elements of Heat Transfer. Third ed., John Wiley and Sons, Inc., 1957, p. 230.

3. Scott, Russell B. : Cryogenic Engineering. D. Van Nostrand Co., Inc. , 1962 , p. 145 . 


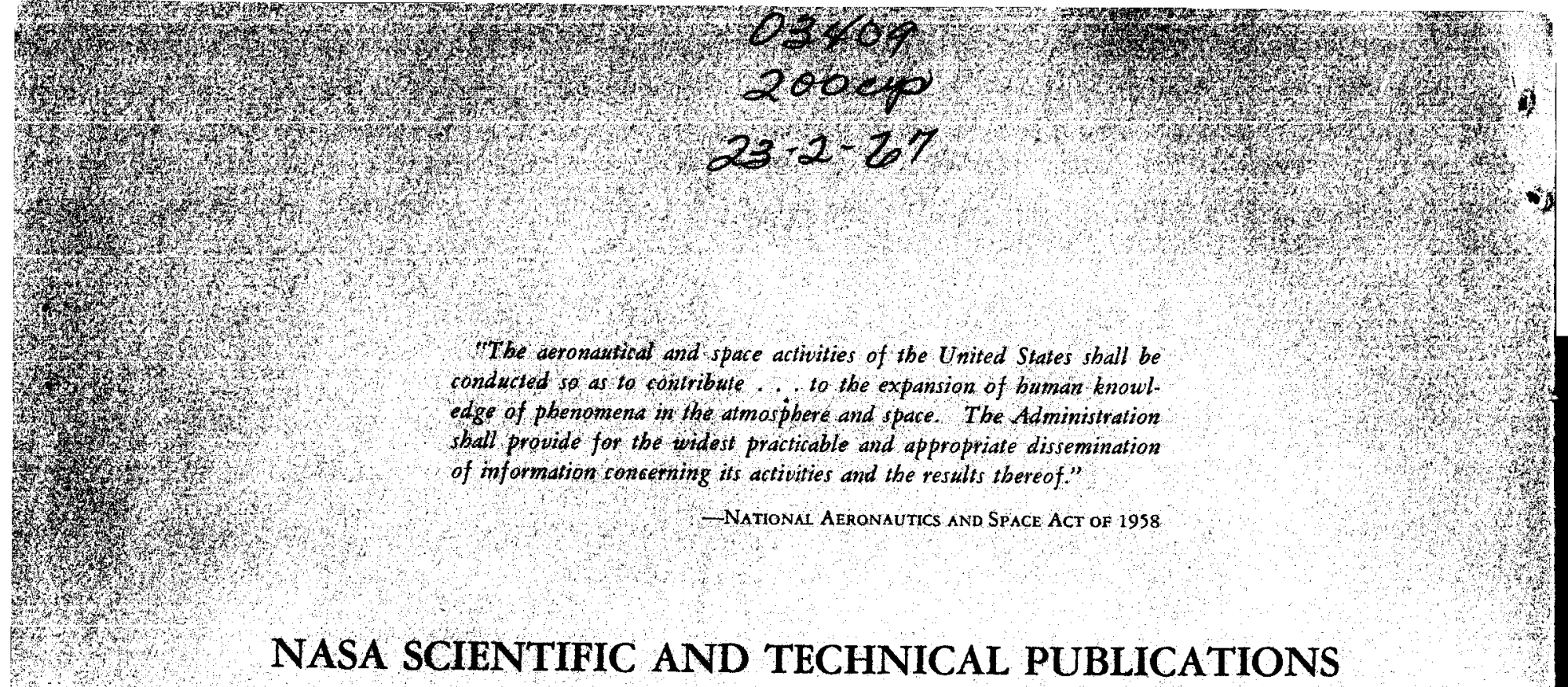

TECHNICAL REPORTS: Scientific and technical information considered important, complete, and a lasting contribution to existing knowledge.

TECHNICAL NOTES: Information less broad in scope but nevertheless of importance as a contribution to existing knowledge.

TECHNICAL MEMORANDUMS: Information receiving limited distribution because of preliminary data, security classification, of other reasons.

CONTRACTOR REPORTS: Technical information generated in connection with a NASA contract or grant and released under NASA auspices.

TECHNICAL TRANSLATIONS: Information published in a foreign language considered to merit NASA distribution in English.

TECHNICAL REPRINTS: Information derived from NASA activities and initially published in the form of journal articles.

SPECIAL PUBLICATIONS: Information derived from or of value to NASA activities but not necessarily reporting the results of individual NASA-programmed scientific efforts. Publications include conference proceedings, monographs, data compilations, handbooks, sourcebooks, and special bibliographies.

Details on the availability of these publications may be obtained from:

SCIENTIFIC AND TECHNICAL INFORMATION DIVISION

NATIONAL AERONAUTICS AND SPACE ADMINISTRATION

Washington, D.C. 20546 